\title{
International Journal of
}

\section{Clinical Obstetrics and Gynaecology}

ISSN (P): 2522-6614

ISSN (E): 2522-6622

(C) Gynaecology Journal

www.gynaecologyjournal.com

2020; 4(6): 242-245

Received: 25-09-2020

Accepted: 27-10-2020

\section{Dr. Rajini Priya}

Associate Professor, Department of obstetrics Gynaecology, Dr.

V.R.K. Women's Medical College,

Teaching Hospital \& Research

Centre. Hyderabad, Telangana, India

\section{Dr. Indira Devi}

Professor, Department of obstetrics \&Gynaecology, Osmania Medical College, Hyderabad, Telangana, India

\section{Dr. Sarojini Devi}

Professor, Head, Department of obstetrics \& Gynaecology, Osmania Medical College. Hyderabad,

Telangana, India
Corresponding Author:

Dr. Rajini Priya

Associate Professor, Department of obstetrics Gynaecology, Dr.

V.R.K. Women's Medical College,

Teaching Hospital \& Research

Centre. Hyderabad, Telangana,

India

\section{The study of local injection of hyaluronidase on cervical dilation in labour-An observational study}

\section{Dr. Rajini Priya, Dr. Indira Devi and Dr. Sarojini Devi}

DOI: https://doi.org/10.33545/gynae.2020.v4.i6d.761

\section{Abstract}

Background: Assessment of the cervical state by palpation has long been the main method of predicting induction of labour and following progress of induced labour, this method gives an approximate measure of the biophysical state of the cervix.

Aim \& Objective: The present study is undertaken to reduce the time taken for the cervical dilation after $3-4 \mathrm{cms}$ to delivery and to evaluate the effect of hyaluronidase on the labour curve of friedmann in primi gravid.

Results: In the present study100 cases were selected, over a period of one year fifty cases were served as hyalase group and fifty as control. In both groups primis and multis were equally sequelae which affect the mother. That the mean injection delivery time in Hyalase group for primigravida and for multigravida are 2 hrs 10 mints and 1 st hour 14 mint. Whereas in control group it is 5 hrs 20 mint and $3 \mathrm{hrs} 10$ mints. It is seen that it is possible to shorten this duration of labour with intracervical Hyalase. Overall study showed that there is a reduction in the duration of labour after injection of intracervical Hyalase at $3 \& 4 \mathrm{cms}$ of cervical dilation and when compared to control group had better APGAR score.

Conclusion: Finally we concluded that, injecting Hyaluronidase intracervical at 3-4 cms. Labour is accelerated by 3.30 mints in primis 2.04 mints in multigravida. It was found safe are economical also.

Keywords: Hyaluronidase, priigravida, multigravida, APGAR

\section{Introduction}

A ripe cervix is expected, when pregnancy comes to "term" occasionally cervix is still unripe, becoming a formiddle challenge to the obstetrician.

The most important factor which determines the duaration of labour cervical dilations. The factors favouring are not adequately understood. Assesment of the cervical state by palpation has long been the main method of predicting induction of labour and following progress of induced labour, this method gives an approximate measure of the biophysical state of the cervix $[1,3]$.

Close correlation of between the clinical course of delivery and the biochemical composition of the cervical connective tissue. In the present study of intracervical hyalase labour is modified at this biochemical level.

Some studies stated that time of labour is proportionate to the state of the cervix. Other factors which determine the course of labour being uterine action presentation of the foetus, the presence or absence of cephalopelvic disproportion ${ }^{[8,9]}$.

Previous studies stated that tightly woven bundles of collagen fibres in the cervix, split; separate and dissolve to a more abundant ground substance during the process of ripening; which is hastened by local infection of hyaluronidase clinical trials have established the efficacy of Hyalase given intracervical in shortening the duration of labour ${ }^{[4,11]}$.

The present study is undertaken to reduce the time taken for the cervical dilation after 3-4 cms to delivery and to evaluate the effect of hyaluronidase on the labour curve of friedmann in primi gravid.

\section{Aim of the study}

This prospective study of the effect of intracervical hyalase on cervical dilation during labour and to study the retrospective results. 


\section{Materials and Methods}

The present study carried out at the Department of Obstetrics \& Gynaecology of Niloufer hospital, during the period of 19951996, effect of intracervical Hyalase on cervical dilation was studied. In this study patients were meticulously analyzed and studied as per a detailed protocol.

Total 100 cases in labour were studied.

No.of Hyalase cases 50

Primi gravid-25

Multigravida-25

No.of Controls-50

\section{Exclusion criteria}

After ruling out cephalopelvic disproportion.

Malpresentaion

Sepsis in the mother

Patients with medical disorders like severe PIH; Rh negative, Diabetes Mellitus were excluded.

Age group of the patients being from 18-35 years. 60-70\% being booked cases of our hospital. Four cases of primigravida with mild pre-eclampsia. In five cases of primigravida only the anterior lip was edematous and thick. A gravid-III with two previous preterm deliveries and cerelage stitch being removed $24 \mathrm{hrs}$ previously, the cases was booked admitted in the ward. In this case hyalase was injected at $3 \mathrm{cms}$ dilation, in this case only the anterior lip was thick and edematous.

In a unbooked case of multigravida with symptoms of accidental hemorrhage and stable general condition. Hyalase was injected into the thick cervical lips at $2 \mathrm{cms}$ dilation, following which artificial rupture of the membrane was done. A case of gravid-III para-II live 2 with previous section who was admitted in the antenatal ward. She was in labour, with vertex presentation, cervix was thick and edematous cervix was $3 \mathrm{cms}$ dilated; after ruling out relative CPD hyaluronidase was injected. Her labour was closely monitored, prophylactic forceps applied. On exploration of uterine seen, found intact.

No cervical trauma noted. In the delivery room, after taking asceptical precautions (vaginal wash with savlon). Cervix was visualized with Sim's speculum, with cervical dilation of 3-4 cms. Inj. Hyaluronidase of strength 30 th per mol, at a dose of 4 $\mathrm{ml}$ (120 IU) was injected at 2o, 60 and 10 o clock positions with a 24 gauge needle.

Repeated pelvic examination was avoided in this study. To avoid sepsis. Interferes with the evaluation of the effect of Hyaluronidase due to ratrogeme stretching of the cervix. Uterine action was monitored every 15 minutes, if uterine inertia occurred oxytocin was administered and the resumption of an effective labour mechanism was taken as the beginning point of the period of further dilation of the cervix. Artificial rupture of membrane done as required in each case. General conditions of the patient monitored every 15 minutes. A I.V life line of ringer lactate kept; oxytocin being added only in cases of uterine inertia. Symptoms OF MATERNAL distress were observed, chiefly those of dehydration and ketosis dry tongue, P.R > 100: rising temperature hot and dry vagina. Prophylactic antibiotics used where indicated.

\section{Results}

Table 1: Duration of labour in Hyalase \& Control group

\begin{tabular}{|l|c|c|}
\hline Duration & Hyalase group & Control group \\
\hline Primigravida length of labour(Hrs: Mts) & $2.10 \mathrm{mts}$ & $5.20 \mathrm{mts}$ \\
\hline Multigravida length of labour (Hrs: Mts) & $1.15 \mathrm{mts}$ & $3.10 \mathrm{mts}$ \\
\hline
\end{tabular}

Friedmann's curve from second stage plotted and delivery time was taken as the end point of observation, programm plotted for each patient, which is a "bird's -eye view", of any given labour, station of the head; degree of effacement and degree of dilation of cervix, uterine contractions- frequency strength, and duration are plotted. In some charts- Analgesics used, B.P; P.R: fluid amounts and space for remarks are recorded.

The delivery concluded with either episiotomy or forceps. Apgar scores of the baby noted patient followed for any complications. In the Hyalase group, there was no sepsis, cervical trauma. Bleeding from the injection site or any postpartum haemorrhage.

Table 2: Following table shows the injection delivery interval

\begin{tabular}{|c|c|c|}
\hline Total & Delivered within 24 hrs & Delivered within 24 hrs \\
\hline \multicolumn{3}{|c|}{ Primigravida } \\
\hline Hyalase Group & $80 \%$ & $100 \%$ \\
\hline Control Group & $20 \%$ & $70 \%$ \\
\hline \multicolumn{3}{|c|}{ Multigravida } \\
\hline Hyalase & $90 \%$ & $100 \%$ \\
\hline Control & $40 \%$ & $75 \%$ \\
\hline
\end{tabular}

When duration of labour is compare with controls, it is seen there is a reduction in the duration of labour after injection of Hyaluronidase, both in the primigravida and multigravida. It is seen from the above table. That the mean injection delivery time in Hyalase group for primigravida and for multigravida are $2 \mathrm{hrs}$ 10 mints and 1 st hour 14 mint. Whereas in control group it is 5 hrs 20 mint and $3 \mathrm{hrs} 10$ mints. It is seen that it is possible to shorten this duration of labour with intracervical Hyalase.

Table 3: Mode of delivery

\begin{tabular}{|c|c|c|c|}
\hline Total & Normal delivery & Forceps & LSCS \\
\hline \multicolumn{4}{|c|}{ Primigravida } \\
\hline Hyalase Group & 87 & 11 & 2 \\
\hline Control Group & 80 & 15 & 5 \\
\hline \multicolumn{4}{|c|}{ Multigravida } \\
\hline Hyalase & 90 & 9 & 1 \\
\hline Control & 85 & 12 & 3 \\
\hline
\end{tabular}

It is seen from the above table that in Hyalase group $87 \%$ of primigravida and $90 \%$ of multigravida had spontaneous labour. Overall study showed that there is a reduction in the duration of labour after injection of intracervical Hyalase at $3 \& 4 \mathrm{cms}$ of cervical dilation and when compared to control group had better APGAR score.

Overall reduction in the duration of labour

Primigravida - 3 hrs 30 mints

Multigravida - $2 \mathrm{hrs} 10$ minta

It is observed that $80 \%$ of primigravida and $90 \%$ of multigravida in Hyalase group delivered at the end of $2 \mathrm{hrs}$. Whereas in control group $20 \%$ and $50 \%$, respectively. At the end of $5 \mathrm{hrs}$ all the cases in Hyalase group delivered. In the control series $35 \%$ of the primigravida and $22 \%$ of multigravida have taken more than $5 \mathrm{hrs}$. The main medication for forceps delivery in hyalase series was poor maternal efforts.

One case of multigravida in Hyalase group had mild atomic $\mathrm{PPH}$, in the absence of any cervical trauma, which was promptly managed with methergine; Syntocinon in 5\% dextrose.

No major complications were observed in Hyalase group. Intracervical Hyalase injection caused to reaction, No sensitivity was noted, and test dose not required no blood loss from the injection site or any cervical trauma. The study was found to be cost effective, each ampoule costing Rs 16.00 reduction in the duration of labour; decrease in the psychological and physical 
exertion in the mother; decreased in the section rate.

The most important outcome in the present study and reduction in the duration of labour, from 3-4 cms of cervical dilation to the birth of baby $3 \mathrm{hrs}$ and 40 mint in primigravida and $2 \mathrm{hrs}$ and 20 mints in multigravida.

Thirty years ago, the incidence of prolonged labour more than 48 hrs was $3 \%$ one should not overlook the residual debility due to prolonged labour i.e late psychological sequelae which affect the mother.

Fetal morbidity i.e. subsequent intellectual capacity of the day. It has been studied, that central nervous system is chiefly affected by prolonged labour. Today with close monitoring the incidence has come down. In the current study of the affect of intracervical hyalase, this objective was delivered. A study conducted at the National Maternity Hospital in Duhlin, in the year 1975, showed that only in three cases labour exceeded $24 \mathrm{hrs}$ in over 2000 primigravidas i.e. an incidence of $0.03 \%$.

\section{Discussion}

In the present study of the effect of intracervical hyalase on cervical dilations. The main underlying biological event being, the action of hyaluronidase a widely distributed endoglycosidase that cleaves, Hexosaminidis linkage from hyaluronidase acid, clinically manifested as ripening of the cervix.

In the present study100 cases were selected, over a period of one year fifty cases were served as hyalase group and fifty as control. In both groups primis and multis were equally sequelae which affect the mother.

Fetal morbidity i.e. subsequent intellectual capacity of the baby. It has been studied, that central nervous system is chiefly affected by prolonged labour. Today with close monitoring the incidence has come down. In the current study of the effect of intra cervical hyalase this objective was achieved. A study conducted at the National maternity hospital in Duhlin in the year 1975, showed that only in three cases labour exceeded 24 hrs in over 2000 primigravidas i.e. an incidence of $0.03 \%$ studied. In the current study the strength of hyaluronidase solution used was $30 \mathrm{IU} / \mathrm{ml}$. It is available in the market in the powder form. It is diluted with normal saline $4 \mathrm{ml}$ containing $120 \mathrm{IU}$ was used at 2,6 , and 10 ' 0 ' clock position. ${ }^{3-7}$

The effect of the hyaluronidase on cervical dilation was previously studied by Philip 1967; Rohith Bhatt et al in $1970^{\text {[1] }}$ and Joseph et al in $1974^{[2]}$. My present study showed more favourable results than the previous study. In Rohith Bhatt 1970 [1], series of 65 cases, 35 cases were of Hyaluronidase group and 30 cases acted as controls and B. Joseph et al . (1974) ${ }^{[2]}$ studied 181 cases, Philip S Green and Rohith V Bhatt ${ }^{[1]}$ study included primigravida and multigravida, But B. Joseph study was conducted only on primigravida ${ }^{[2]}$.

Joseph et al used 300 in for one case i.e $300 \mathrm{IU} / \mathrm{ml}$. In their study Hyaluronidase was injected at four positions i.e. 1, 2, 3, and 9 o clock position. In the Rohith $\mathrm{V}$ Bhatt and Joseph et al study, cases were selected after ruiling out CPD: fetal malpresentation, any complications in the mother.

In the current study, five cases of mild PIH were included in the Hyaluronidase group. A case of multigravida with extended breech was also studied. In all these cases and particularly in cases were only the anterior lip was thick and edematous responded well with intracervical injection of hyaluronidase only one case of multigravida, had mild atomic PPH, without any cervical trauma, which wa well controlled.

According to Friedmann's mean labour curve (1955) the time taken for the primigravida in labour from $4 \mathrm{cms}$ cervical dilation to the birth of the baby is $4 \mathrm{hrs}$ and 15 mints. In the present study the primigravida who received intracervical hyaluronidase injection, the mean labour time from $4 \mathrm{cms}$ cervical dilation to the delivery of the baby is $2 \mathrm{hrs}$ and 20 mints.

In Rohith V Bhatt ${ }^{[1]}$ study the duration of labour was reduced by $3 \mathrm{hrs}$ and 10 mints in primigravida and $3 \mathrm{hrs}$ and 50 mints in multigravida. In B.Joseph (1974) ${ }^{[2]}$ study it was $2 \mathrm{hrs}$ and 7 Mints. ${ }^{2}$ In Green's study the duration of labour was reduced by $2 \mathrm{hrs}$ in primigravida and one hour in mutigravida.

In Rohith V Bhatt et al. ${ }^{[1]}$ study in Hyaluronidase group $75 \%$ of the primigravida and $88 \%$ of the multigravida delivered within 6 hrs. When compared to their study, in the present study all the primigravida and multigravida delivered within five hrs of intracervical hyaluronidase, these favourable results due to use of oxytocin and artificial rupture of the membranes used in the current study.

There were no maternal complications in the hyaluronidase group of present study. B. Joseph (1974) ${ }^{[2]}$ had one traumatic and atomic PPH in his hyadronidase series.

Maternal complications such as transient giddiness paraesthesia and weakness of limits, pelvic abscess were encounted with the paracervical block, but such maternal complications were not seen with hyaluronidase [12, 13]. In Sreemathy series of paracervical block with periodic vaginal examination, the incidence of forceps delivery was nearly $40 \%$. The incidence of foetal bradycardia was $6 \%$, with paracervical block, but with hyaluronidase the incidence of foetal bradychardia is nil. Hence in view of these maternal and foetal complications with paracervical block, the intracervical injection of hyaluronidase is safer and more beneficial procedure.

\section{Conclusion}

In this study of 100 cases it is seen that injecting Hyaluronidase intracervical at 3-4 cms. Labour is accelerated by 3.30 mints in primis 2.04 mints in multigravida. It was found safe are economical also, specially in cases were cervical lips are thick others parameters being within normal limit.

\section{Acknowledgment}

The author thankful to Department of OBG for providing all the facilities to carry out this work.

\section{Conflict of Interest: Nil}

\section{Financial Support: Nil}

\section{References}

1. Rohith V Bhatt. IJOG 1971.

2. Joseph Chandra B. I.J.O.B, Oct 1974.

3. Boulvain M, Stan C, Irion O. Membrane sweeping for induction of labour. Cochrane review. The Cochrane Library 2004;(1). [Update software].

4. Kelly AJ, Kavanagh J, Thomas J. Relaxin for cervical ripening and induction of labour. Cochrane Review. The Cochrane Library 2004;(1). [Update software].

5. Thomas J, Kelly AJ, Kavanagh J. Oestrogens alone or with amniotomy for cervical ripening and induction of labour. Cochrane review. The Cochrane Library 2004;(1). [Update software].

6. Matti JKG, Horobin DF, Branley PS. Induction of labour in sheep and in humans by single doses of corticosteroids. $\mathrm{Br}$ Med J 1973;2:149-51.

7. Satin AJ, Leveno KJ, Sherman ML, Mcintire DD. Factors affecting the dose response to oxytocin in labor stimulation. J Obstet Gynecol 1992;166:1260-1. 
8. Sanchez-Ramos L, Kaunitz AM, Del Valle GO, Delke I, Schroeder PA, Briones DK et al. Labor induction with the prostaglandin E1 methyl analogue misoprostol versus oxytocin: a randomized trial. Obstet Gynecol 1993;81:3326.

9. Aquino MMA, Cecatti JG. Misoprostol versus oxytocin for labor induction in term and post term pregnancy. Randomized controlled trial. São Paulo Med J 2003;121:102-6.

10. Rath W, Theobald P, Kühnle H, Kuhn W, Hilgers H, Weber $\mathrm{L}$, et al. Changes in collagen content of the first trimester cervix uteri after treatment with prostaglandin F2a gel. Arch Gynecol 1982;231:107-10.

11. Bugalho A, Bique C, Machungo F, Faúndes A. Low-dose vaginal misoprostol for induction of labor with a live fetus. Int J Gynaecol Obstet 1995;49:149-55.

12. Wing DA, Rahall A, Jones MM, Goodwin TM, Paul RH. Misoprostol: an effective agent for cervical ripening and labor induction. Am J Obstet Gynecol 1995;172:1811-6.

13. Wing DA, Paul RH. A comparison of differing dosing regiments of vaginally administered misoprostol for preinduction cervical ripening and labor induction. Am J Obstet Gynecol 1996;175:158-64. 